\title{
Tactics Thinking of Outstanding Traditional Culture Education of Tourism Management Specialty in Colleges and Universities
}

\author{
Xiaoliang Chen * \\ Tourism and Urban Management College \\ Jiangxi University of Finance and Economics \\ Nanchang City, Jiangxi Province, China \\ E-mail: jxchenxiaoliang@163.com
}

\begin{abstract}
As a symbol of historical civilization and social progress and as an important ideological and cultural resource for managing state affairs, excellent traditional culture and education in the revival of national culture and the promotion of quality education in the context of reality, has demonstrated its actual effectiveness and historical significance. However, there are many tendencies to neglect the study of excellent traditional culture and run counter to the enhancement of the overall quality of students in tourism colleges and universities. This article analyzes many problems existing in the excellent traditional culture education of tourism management specialty in colleges and universities, and puts forward new ideas in terms of curriculum establishment, inheritance and promotion of outstanding traditional culture, creative transformation and innovative development, and internationalization and integration of development, providing reference to Carry Out Excellent Traditional Culture Education in Tourism Management Specialty of Colleges and Universities.
\end{abstract}

Keywords-Tourism management specialty; Traditional culture education; Analysis; Strategy

\section{INTRODUCTION}

In early 2017, the CPC Central Committee General Office and the State Council General Office issued the Opinions on Implementing the Project of Inheriting and Developing Chinese Excellent Traditional Culture, which stated that the implementation of the excellent traditional Chinese cultural heritage development project is a major strategic task of building a strong socialist culture. This is of great significance to the inheritance of the Chinese context, the overall promotion of the cultural awareness of the people, the safeguard of the national culture, the enhancement of the national cultural soft power, the promotion of the state governing system and the modernization of governance capacity. This opinion runs through national education from beginning to end, enriching and expanding campus culture, promoting the opening of open classes of Chinese culture and displaying the achievements of traditional culture and education. In early July of the same year, the office of the National Tourism Administration issued the "Outline for the Development of Talents in Tourism during the 13th Five-year Plan", urging them to make overall plans to promote five tourism administration talents, enterprise management personnel, professional and technical personnel, skilled personnel and practical talents for rural tourism Talent team building. With the rapid development of the current tourism service industry, the demand for high-quality personnel from tourism is expanding day by day. The training and construction of tourism management professionals are increasingly showing the urgency of the times. Tourism will be the most promising industry.

Tourism management is a service management professional, major span, a wide range of knowledge, strong cultural integration. Tourism education covers economics, management, history, geography, planning, ecology and other disciplines. Requirements for graduates of tourism professional training programs require that students have strong ability of writing, language communication, information acquisition and foreign language communication; good teamwork and organization and management skills; strong professional practice and practical ability Good at finding problems and problem-solving skills; Good at learning, with basic literature retrieval, data query, statistical analysis and other basic scientific research capabilities; have a certain degree of innovation and entrepreneurship practice ability. Therefore, graduates of tourism management will be highly qualified and comprehensive talents with rich theory, extensive knowledge and strong adaptability. They will not only be able to handle the relevant posts in the three pillar industries of travel agencies, tourist hotels and tourism and transportation Served as a non-tourism industry service management class job. The specialty of this specialty determines the necessity of the construction and implementation of excellent traditional culture and education in this major.

\section{The STATUS QUO AND PROBLEMS}

Tourism characteristics in colleges and universities are characterized by the integration of higher education and tourism education and relying on local colleges and universities to fully rely on the advantages of subjects, focusing on the characteristics of tourism specialty training direction, taking into account the relevant subjects of tourism, the formation of distinctive features, significant advantages, and disciplines based training system. However, tourism management students have long been keen on turning professional study, neglecting the study of this major and 
forcing employment across industries due to employment pressure. In the aspect of teaching and training, in the face of the increasingly fierce competition for talent market demand and the development of tourism management Programs become more and more blindly depending on the demand of specialized technology and often underestimate the requirements of excellent traditional cultural quality cultivation. And even tourism management professionals are beginning to discuss the issue of whether or not to set the excellent traditional culture specialty courses in this specialty. In the meantime, at the practical level, under the impact of the marketization of the tourism industry, the tourism industry frequently shows negative news such as unsafe tourism infrastructure, irregular tourism services and uncivilized behavior of tourists.

On the one hand, from the perspective of social environment, the values of modern Chinese society have undergone great changes. In the traditional teaching system, the scope of the study of Chinese traditional culture includes the sum of the material, spiritual, institutional, and behavioral cultures created by all ethnic groups within the scope of the People's Republic of China since its own history. An examination of the basic traits of Chinese traditional culture can be based on the fact that China differs from the characteristics of other countries' cultures. It can also be based on the basic social features of the natural economy and blood clan patriarchal system of the ancient Chinese traditional society. Chinese traditional culture is famous throughout the world for its pragmatic theoretical features of focusing on ethics, morality first, pursuing harmony and unity, promoting rational spirit, and promoting humanistic education but not yet mysterious and pragmatic. ${ }^{1}$

However, in modern society, with the social transformation, the values of culture and people are also changing. In daily life, the meaning of life is often overshadowed or even absent. Technicalism, hedonism and nihilism have become the fundamental aspects that govern people's lives. People have formed a kind of unconscious instinct that is to use utilitarian standards to measure everything, "useful" or not as a measure of the existence of meaning and value of things. At the same time, Western society and Chinese society in modern society have a tendency of secularization. With the liberation of mankind and the development of natural science, the spiritual idols and the external divine power collapse, the natural forces of mankind's transformation are strengthened, the denial of anything that can't be confirmed now, the fear of nothing, and the spiritual homeland The general impulsiveness of the state of mind, the ideal and the faith gradually indifferent. Moreover, since the reform and opening up in China, people's values have shown a tendency to diversify for many reasons. Educators inevitably suffer from non-mainstream culture and ideology from the community and family, resulting in a wide range of values. Visible, utilitarian, secular, and pluralism are constantly leading and affecting the mainstream values of modern society. $^{2}$

\footnotetext{
${ }^{1}$ Chen Jiangfeng Introduction to Chinese Traditional Culture [M], Beijing University of Aeronautics and Astronautics Press,2010:5.

${ }_{2}^{2}$ Gao Qiong,Liu Ru, China's traditional culture and education of the status quo and Countermeasures [J]. Education and Research,2008 (5).
}

On the other hand, from the perspective of both the main educational activities carried out by educators and educators, contemporary college students have a series of problems in accepting excellent Chinese traditional culture and education. ${ }^{3}$ Firstly, educators have problems with the recognition of excellent Chinese traditional culture. In today's social environment, multiculturalism in online communication has a very strong impact on educated children. For young people whose world outlook is still in its formative stage, it is not uncommon for universities to ignore or even resist traditional cultural ideology. Secondly, educators have weakened the outstanding Chinese traditional culture and education. In order to meet the needs of the market, college education often focuses on practical skills in personnel training programs and curricula. The employment rate and annual income of graduates are used as indicators to test the training of talented people, the direction of quick success, or More or less, the traditional Chinese culture and education in colleges and universities continue to weaken the function.

Therefore, it can be said that there are many reasons why there are many difficulties for college students in traditional culture education. Firstly, it is the result of the interaction of various internal and external factors. Secondly, as far as schools are concerned, the dilemma of traditional culture and education is not unrelated to the sound management mechanism. Finally, the lack of parents' traditional concepts and related knowledge is also an important factor in the lack of traditional culture and education of college students. ${ }^{4}$

\section{STRATEGIC THINKING}

The report of the 19th National Congress of the Communist Party of China mentions that we must accelerate the construction of first-class universities and first-class disciplines and achieve the connotative development of higher education. In the education of colleges and universities, we can't neglect to inherit and carry forward the excellent Chinese traditional culture. The excellent Chinese traditional culture has always been the "root" and the "soul" of the Chinese nation.

\section{A. Attach importance to the excellent traditional culture curriculum of tourism management specialty.}

Traditional culture is the spiritual education of personnel training in colleges and universities. The setting of tourism specialty traditional culture courses can enhance students' cognition of traditional culture knowledge and cultivate their professional identity.

In the traditional Chinese culture, it is worth learning a lot of essences. It covers only the quality education: lofty sense of historical mission and sense of responsibility; lenient treatment of others, strict self-discipline; patriotism and open mindedness; proactiveness, Self-cultivation and other fine traditions of the Chinese nation. Due to the specialties of its own major, tourism management major has always been concerned about the education and influence of students on the tourism history and

\footnotetext{
${ }^{3}$ Wang Dongmei,Guo Xiaoliang,Zhou Dang. Problems and Countermeasures in Chinese Excellent Traditional Culture Education in Colleges and Universities [J]. Journal of Liaoning Institute of Technology (Social Science Edition), 2017 (3).

${ }^{4}$ Kong Deli, Li Yan, under the background of globalization, the difficulties and countermeasures of college students' traditional culture education [J]. Beijing Education,2013(11).
} 
culture in their traditional subject setting. Among them, the excellent traditional tourism culture is the concentrated essence of the long-term accumulation of tourism history, the professional improvement of excellent traditional culture, and the cultural foundation of the tourism teaching system. Therefore, in the setting of professional main courses, we can't underestimate the setting of traditional culture courses.

\section{B. Emphasis on professional characteristics of cultural transmission and inheritance of tourism management major.}

The excellent Chinese traditional culture embodies the centripetal force of the nation as well as cultural self-esteem, self-confidence and self-awareness, and represents the spiritual pillar of the entire nation. Its dissemination and inheritance are the most important parts of China's development at present. Neither can it be neglected, nor can it be eager for quick success.

Tourism Management students, both during the study and practice or into professional jobs, has served as a messenger of outstanding traditional culture. From the perspective of communication studies, the main body of communication provides information flow to the audiences, and then the audiences make judgment according to their own specific cultural and value background, and make judgment through the selection, digestion and absorption of this information, and reach public opinion through the collective expression. The tourism industry upholds the characteristics of cultural transmission, the reputation of tourist destinations for tourist destinations, credibility and its composition, all have affected the public's evaluation and impression of tourist destinations. However, the spread and inheritance of excellent traditional culture are confronted with multiple challenges such as new media, the wave of globalization and cultural pluralism.

Therefore, in the extracurricular activities of students, enriching the traditional culture and education by creating a variety of extra-classroom teaching forms, leveraging the Internet platform, creating traditional cultural activities on campus, increasing the attractiveness of traditional culture and education, and stimulating students' Seeking the desire to cultivate the students 'national spirit, enhance students' traditional cultural accomplishment, and achieve the purpose of promoting the traditional culture of communication and inheritance.

\section{Tourism Management Training students to learn}

outstanding traditional culture at the same time, we must

know how to creatively transform traditional culture and innovative development.

At present, the conventional talents of tourism management specialty are relatively saturated and the social demand of innovative talents is constantly increasing. In the actual tourism talent training program settings, tourism management professionals continue to try to research projects as the starting point to start a business union as a platform to student academic mentor and student entrepreneurship guidance system for the specific implementation of the path to jointly create teachers and students scientific research groups and Student entrepreneurship network system to enhance student creativity, innovation and entrepreneurship. The creative transformation and innovative development of traditional culture knowledge are also the embodiment of innovative talent cultivation concept.

\section{The tourism management profession does not mean to be} self-reliant when it inherits and carries forward the fine traditional Chinese culture.

This is exactly the reason why the current tourism management major is gradually exploring ways to train international professionals, to study international specialization trends and to explore internationalization Reform measures. Internationalization of higher education refers to the purpose, function and provision of international latitude, intercultural latitude and global latitude into higher education at both institutions and countries. Through years of development, some colleges and universities tourism management professional has come out of the path of internationalization. In the aspects of joint schooling, internship and exchange of students, organizing and participating in international academic conferences and visits by teachers, the tourism management major has a great competitive advantage compared with other specialties due to its particularity. This is a more open, inclusive and distinctive feature for students to improve their connotation and expand their outstanding qualities of traditional culture.

\section{E. Tourism management professionals should try to combine} the connotation of traditional culture with the needs of social development and practice the concept of integration and development.

This concept points the way to the succession and development of outstanding traditional culture. The Chinese traditional culture is profound, and the content system of its higher education is not immutable. Attention is paid to the construction and development of knowledge system of interdisciplinary education in higher education. Tourism management professionals at home and abroad have gradually established a multidisciplinary field of history, geography, literature, philosophy, sociology, economics, management science, ecology and statistics Knowledge System. Under the current trend of rapid updating of knowledge structure, the development, innovation and integration of excellent traditional culture need the support and promotion of multidisciplinary fields. Therefore, this can be from the construction and development of teaching staff, personnel training programs continue to improve, the optimization and innovation of professional curriculum content, student internships and practical training and guidance and other aspects, to continuously enrich and improve the connotation and extension of traditional culture education of the excellence of tourism management.

\section{CONCLUSION}

The report of the 19th Chinese Communist Party Congress proposed that education should be prioritized. Building a Powerful Country for Education is the Foundation Project for the Great Rejuvenation of the Chinese Nation. Education must be given priority so that education modernization can be accelerated and education satisfactory to the people can be 
satisfactorily implemented. Tourism management major should be rooted in the national characteristics, learn from the experience of traditional culture and education at home and abroad, so that students can't only enhance the traditional cultural qualities, but also contribute to the exchange of international culture. In modern society, the cultural accomplishment of employees in the tourism industry is directly related to the rise and fall of survival and survival of tourism enterprises and the operation and development of the industry. The higher the degree of social civilization development, the higher the requirement of cultural accomplishment. As a high-level human civilization, colleges and universities carry the heavy responsibility of traditional culture and education. Only by attaching great importance to cultivating the outstanding traditional cultural qualities of tourism management professionals can we promote the sustainable development of tourism.

\section{REFERENCES}

[1] Chen Jiangfeng. Introduction of Chinese traditional culture[M], Beijing University of Aeronautics and Astronautics Press,2010:P5.(In Chinese)

[2] Gao Qiong, Liu Ru. China's traditional culture and education of the status quo and Countermeasures [J]. Education Research,2008 (5).(In Chinese)

[3] Wang Dongmei, Guo Xiaoliang, Zhou Dang. Problems and Countermeasures in Chinese Excellent Traditional Culture Education in Colleges and Universities [J]. Journal of Liaoning Institute of Technology (Social Science Edition), 2017 (3).(In Chinese)

[4] Kong Deli, Li Yan. Under the background of globalization, the difficulties and countermeasures of college students' traditional culture education [J]. Beijing Education,2013(11).(In Chinese)

[5] Propaganda Department of the Central Committee of the Communist Party of China, General Secretary Xi Jinping series of important speech reader [M], learning press, People's Publishing House,2016.(In Chinese)

[6] "Tutorial reader of the report of the party's Nineteenth Congress" compilation group, the report of the party's Nineteenth Congress [M]. People's Publishing House,2017.(In Chinese) 